\title{
Unusual and nondescript type of distal clavicular fracture
}

\author{
Alberto Izquierdo Fernández, José Carlos Minarro \\ Department of Traumatology and Orthopedic Surgery, Hospital Universitario Reina Sofía, Córdoba, Spain
}

\begin{abstract}
Displaced fracture of the distal third of the clavicle usually occurs after direct trauma to the shoulder and typically results in superior displacement of the proximal fragment. We report a previously undescribed case of downward displacement of the clavicle caused by a fall on an outstretched hand, and we suggest the mechanism of injury.
\end{abstract}

Keywords: Clavicle; Fracture; Fracture fixation, internal

Distal clavicle fractures have been classified by many authors, and the most accepted classification was proposed by Neer [1]. When present, fracture displacement is conditioned by the weight of the arm that displaced the distal fragment downwardly and by insertion of the trapezius muscle to move the proximal fragment superiorly. We present an unusual case of inferior displacement of the proximal fragment with indemnity of the coracoclavicular ligaments, and we propose the mechanism of injury.

\section{CASE REPORT}

The patient signed the informed consent provided by our institution. A 15-year-old male sustained a painful right shoulder injury following a fall from a bike onto an outstretched hand. Physical examination showed pain and swelling at the level of the distal clavicle and disclosed no neurovascular injuries. The radiographic exam, including a Zanca view, showed an unstable fracture of the distal clavicle with decreased coracoclavicular distance. The proximal fragment of the fracture was displaced inferiorly and slightly posteriorly onto the supraspinatus fossa. There was no contact between the ends of the fracture (Fig. 1). A three-dimensional computed tomography (CT) reconstruction showed a decrease in distance between the clavicle and coracoid process, suggesting that the coracoclavicular ligaments were unaffected. The distal fragment showed an increase of 10-11 mm, within the normal limit (Figs. 2 and 3), and slight posterior displacement (Fig. 4).

As contact between fragments was not appreciated, the risk of nonunion was considered high, so surgical treatment was chosen. Using a superior approach, we performed an open reduction and internal fixation. For osteosynthesis, we use an locking compression plate distal clavicle plate (DePuy Synthes, Bridgewater, MA, USA) (Fig. 5). The integrity of the coracoclavicular ligaments, revealed during surgery, was intact but stretched. The injured limb was immobilized in a sling for three weeks, after which the patient began a specific rehabilitation treatment. Ten weeks after surgery, fracture healing was observed on the X-ray

Received: March 22, $2021 \quad$ Revised: April 21, $2021 \quad$ Accepted: April 24, 2021

Correspondence to: Alberto Izquierdo Fernández

Department of Traumatology and Orthopedic Surgery, Hospital Universitario Reina Sofía, Av. Menéndez Pídal sn, Córdoba 14004, Spain

Tel: +34-667789977, E-mail: alberto.izquierdo.fer@hotmail.com

Financial support: None.

Conflict of interest: None.

Copyright@ 2021 Korean Shoulder and Elbow Society.

This is an Open Access article distributed under the terms of the Creative Commons Attribution Non-Commercial License (http://creativecommons.org/licenses/by-nc/4.0/) which permits unrestricted non-commercial use, distribution, and reproduction in any medium, provided the original work is properly cited. 


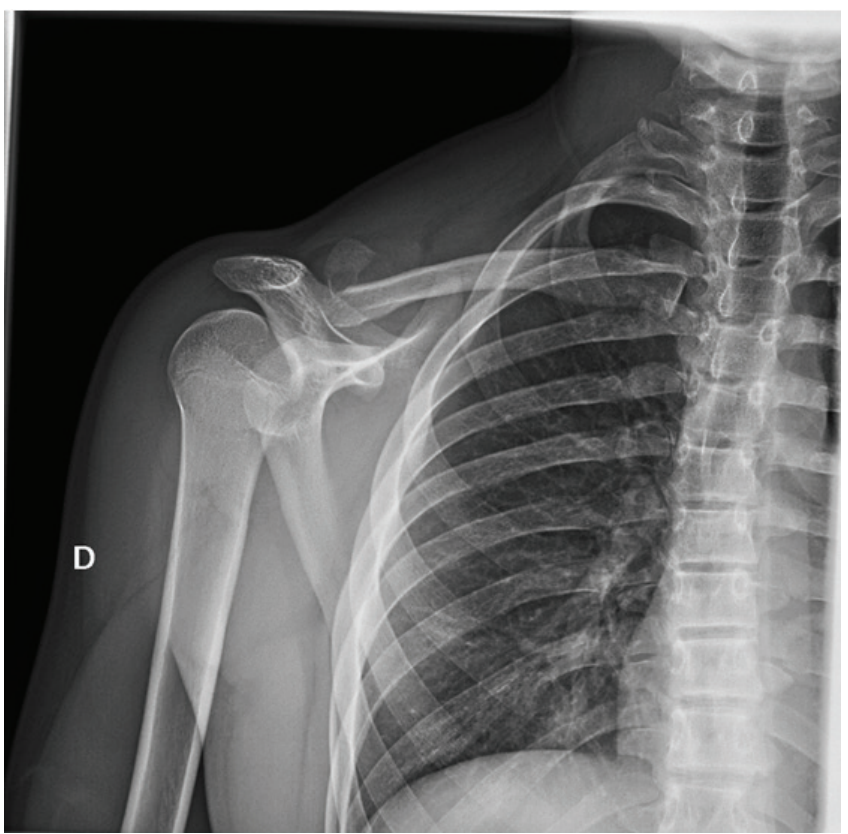

Fig. 1. Radiographic exam showing an unstable fracture of the distal clavicle.

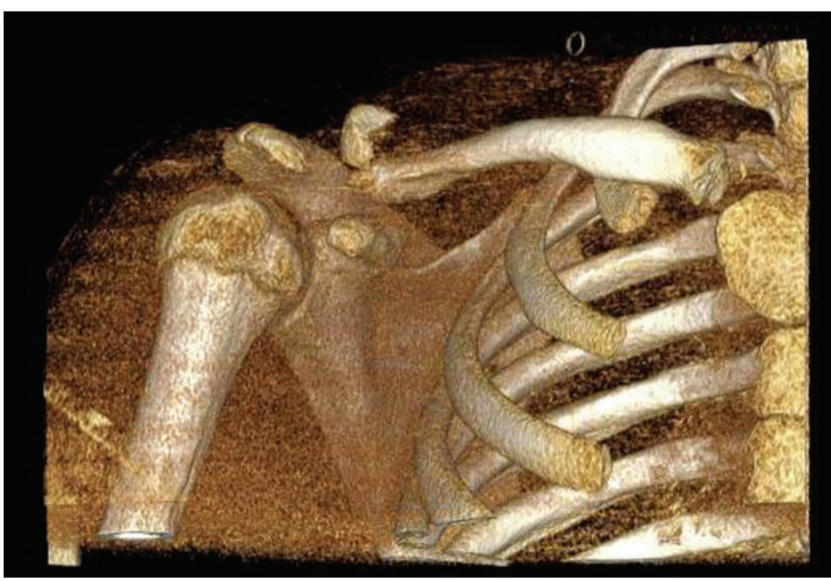

Fig. 2. Computed tomography scan. Three-dimensional reconstruction.

exam, and the patient reached a pain-free range of motion.

\section{DISCUSSION}

Many authors have proposed classification systems for clavicle fractures. Allman [2] classified clavicle fractures into three types based on anatomical location without considering treatment or prognostic significance. Nordqvist and Petersson [3] broadened Allman's classification according to degree of displacement. Robinson [4] classified clavicle fractures base on joint involvement. The most accepted classification, described by Neer [1] and de-

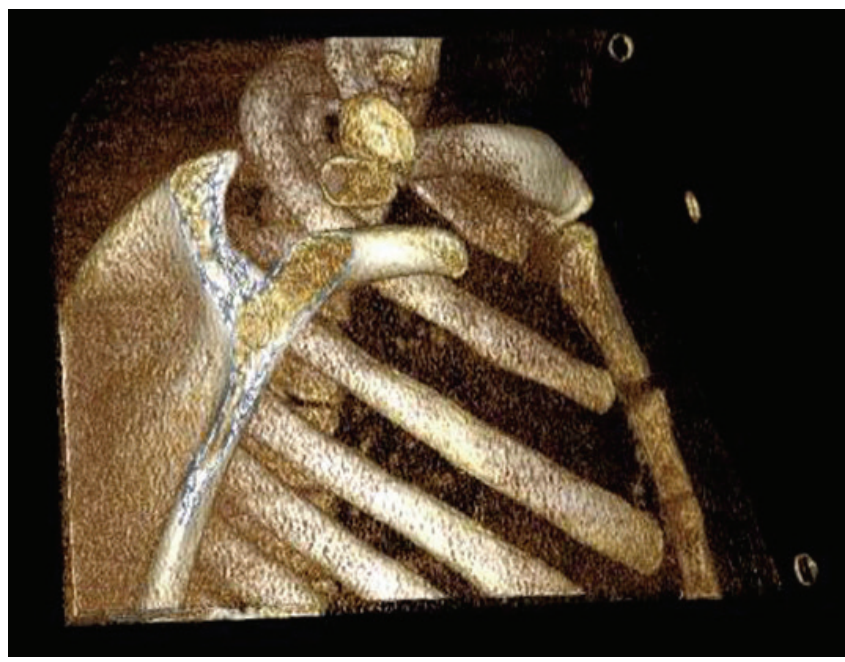

Fig. 3. Computed tomography scan. Three-dimensional reconstruction.

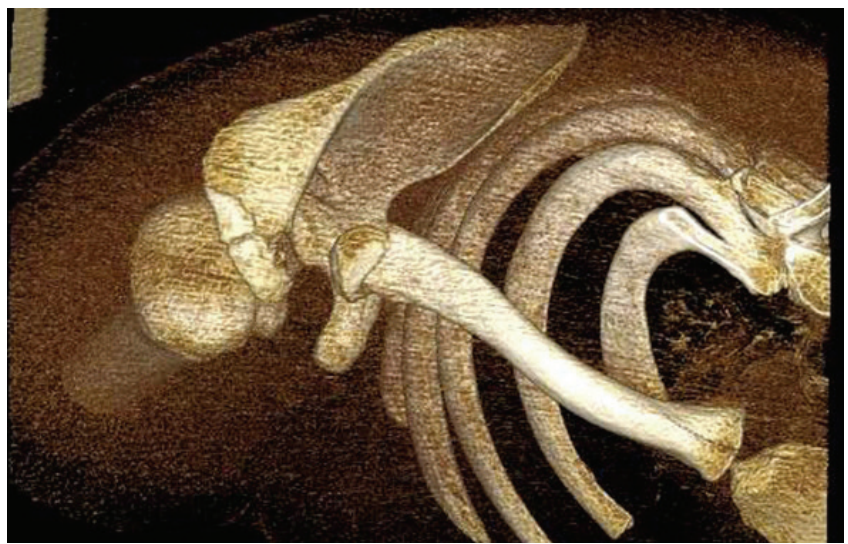

Fig. 4. Computed tomography scan. Three-dimensional reconstruction showing minimal posterior displacement.

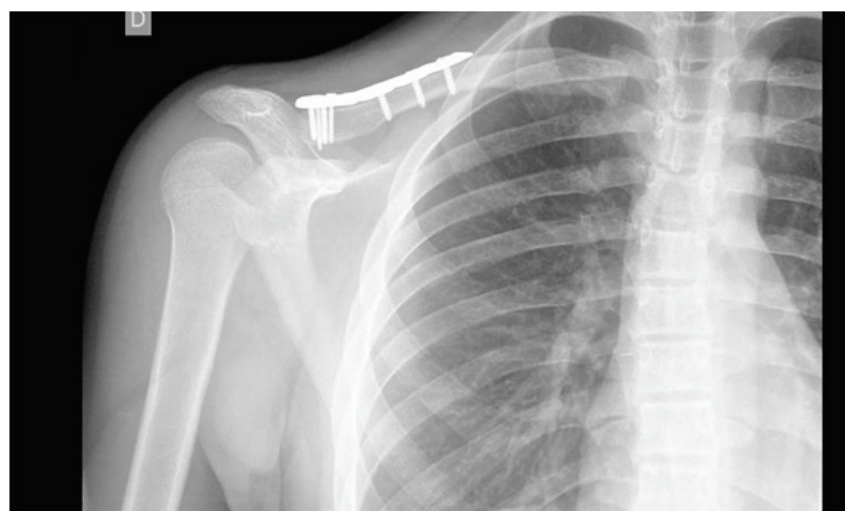

Fig. 5. Postoperative radiographic exam.

scribed by Rockwood [5], added two subtypes to describe five types of fractures of the distal clavicle. Type I fracture occurs lateral to the coracoclavicular ligaments attachment with minimal 
displacement. Fractures of this type are subject to conservative treatment. A type II fracture is medial to the ligament attachment and is divided into IIA and IIB. In IIA, both coracoclavicular ligaments are attached to the distal fragment, while in IIB, the conoid is detached from the proximal fragment of the fracture while the trapezoid remains attached to the distal fragment. Type III is an intra-articular fracture. Type IV occurs in children when a periosteal sleeve avulses from the inferior side of the clavicle with the attached coracoclavicular ligaments. Similar to type II, type $\mathrm{V}$ is a fracture with an avulsion that leaves behind an inferior cortical fragment attached to the coracoclavicular ligaments. In types II, IV, and V, the proximal fragment is displaced superiorly by the action of trapezius muscle.

In the present case, the fracture was lateral to the insertion of the coracoclavicular ligaments, so it would be classified as a type I clavicular fracture. Type I fractures, however, have minimal displacement, so it is difficult to classify our case into this group. Furthermore, although this case could be considered a type IV variant given the age of the patient, the superior displacement of the medial fragment and the complete ossification of the epiphyseal cartilage exclude this type.

The mechanism of injury most often associated with a clavicle fracture is a direct blow to the shoulder. The compressive strength causes the fracture and the usual displacement of the fragments [6]. We suggest that the mechanism of injury in this case is different than usual because the patient reported a fall onto an outstretched hand, an indirect mechanism in which a force applied through the upper limb causes an increase of the proximal humerus and promotes injury. This mechanism has been reported previously as a rare cause of clavicle fracture in only $6 \%$ of cases [6].

An indirect mechanism has been reported in some cases of acromioclavicular dislocation [7]. Upward force applied to the humerus disrupts the acromioclavicular ligaments. This mechanism causes downward displacement of the clavicle, corresponding to type VI of Rockwood's classification [8]. Inferior dislocation of the distal end of the clavicle is rare, often is the result of severe trauma, and is combined frequently with multiple injuries. In type VI clavicle fractures, the coracoclavicular ligaments are intact if displacement of the proximal fragment is subacromial or torn if it is subcoracoid [7]. We suggest that the mechanism of injury in the present case is similar to that of type VI of Rockwood's classification but does not involve ligament rupture. In our case, instead of acromioclavicular dislocation, there is a fracture of the distal clavicle with inferior displacement of the medial fragment (Fig. 6).

The literature does not reveal any cases similar to ours. One

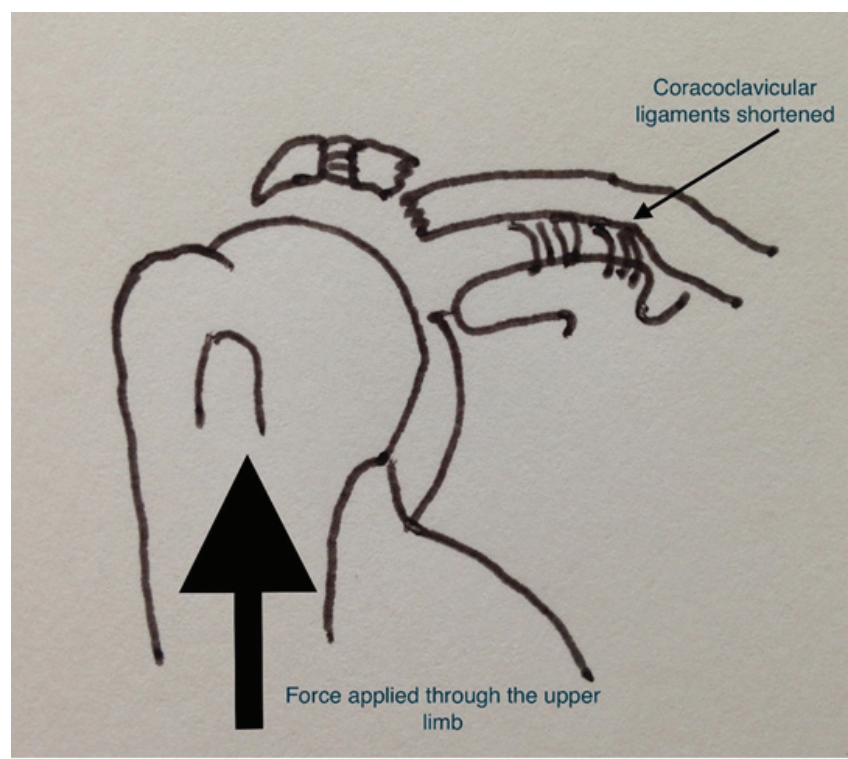

Fig. 6. Suggested mechanism of injury. The arrow shows the direction of the traumatic force.

report described two cases with a similar pattern of fracture but with coracoclavicular ligaments rupture [9]. Following the existing classifications for fractures of the distal clavicle, our case corresponds to type I of Neer's classification and should be susceptible to conservative treatment. The large displacement caused by the unusual indirect mechanism, however, prompted osteosynthesis, with an excellent functional outcome.

\section{ORCID}

Alberto Izquierdo Fernández https://orcid.org/0000-0002-4270-0852 José Carlos Minarro https://orcid.org/0000-0002-4491-0124

\section{REFERENCES}

1. Neer CS 2nd. Fractures of the distal third of the clavicle. Clin Orthop Relat Res 1968;58:43-50.

2. Allman FL Jr. Fractures and ligamentous injuries of the clavicle and its articulation. J Bone Joint Surg Am 1967;49:774-84.

3. Nordqvist A, Petersson C. The incidence of fractures of the clavicle. Clin Orthop Relat Res 1994;(300):127-32.

4. Robinson CM. Fractures of the clavicle in the adult: epidemiology and classification. J Bone Joint Surg Br 1998;80:476-84.

5. Rockwood CA. Fractures of the outer clavicle in children and adults. J Bone Joint Surg Br 1982;64:642.

6. Stanley D, Trowbridge EA, Norris SH. The mechanism of clavicular fracture: a clinical and biomechanical analysis. J Bone Joint Surg Br 1988;70:461-4. 
7. Stucken C, Cohen SB. Management of acromioclavicular joint injuries. Orthop Clin North Am 2015;46:57-66.

8. Williams GR, Nguyen VD, Rockwood CA. Classification and radiographic analysis of acromioclavicular dislocations. Appl
Radiol 1989;18:29-34.

9. Fang YP, Lin GY, Tarng YW, Lin KC. Unusual types of distal clavicular fractures: two case reports. Radiol Case Rep 2015; 7:606. 